\title{
Temporal Trend of the Major Contributors for the Particulate Polycyclic Aromatic Hydrocarbons (PAHs) in Seoul
}

\author{
Sanghee Han ${ }^{1}$, Ji Yi Lee ${ }^{1}$, Jongbae Heo ${ }^{2 *}$, Yong Pyo Kim ${ }^{3 * *}$ \\ ${ }^{1}$ Department of Environmental Science and Engineering, Ewha Womans University, Seoul 03760, Korea \\ ${ }^{2}$ Department of Environmental Health, Seoul National University, Seoul 08826, Korea \\ ${ }^{3}$ Department of Chemical Engineering and Materials Science, Ewha Womans University, Seoul 03760, Korea
}

\begin{abstract}
To evaluate the effectiveness of the air quality management policies in Northeast Asia, especially in China and South Korea, temporal variation in the major contributors of the observed particulate polycyclic aromatic hydrocarbons (PAHs) in Seoul between 2002 and 2013 was estimated via receptor modeling. In addition, analyses of the air parcel movement and the statistics related to energy usage and PAH emissions in the region were conducted to validate the modeling results. Five factors were identified: coal usage for coke ovens, residential coal use, vehicular emission, biomass burning, and other emission sources. It was found that the PAH concentration in the ambient air in Seoul has been affected not only by domestic emissions but also by transported PAHs originating outside Korea, such as emissions from coal use in China and biomass burning in Northeast Asia. In addition, the impact from North Korea was verified for the PAHs emitted from biomass burning. The contribution of coal combustion decreased while that of vehicular sources increased during the study period; the contribution from biomass burning, however, remained consistent. Despite uncertainties in the modeling results, which are discussed in this paper, this study demonstrates that the air quality management policies in China and South Korea have been successful in reducing particulate PAH emissions.
\end{abstract}

Keywords: Polycyclic aromatic hydrocarbon (PAH); Positive matrix factorization (PMF); Major contributor; Northeast Asia; Emission trends; Air quality management policy.

\section{INTRODUCTION}

Ambient air quality in Seoul is affected by air pollutants emitted both from Seoul proper and outside of Seoul, notably Korea and Northeast Asian countries (see, for example, Lee and Kim, 2007). Kim (2006) examined the measurement and modeling results of the early 2000s and estimated the atmospheric particulate matter with an aerodynamic diameter of less than or equal to a nominal $10 \mu \mathrm{m}\left(\mathrm{PM}_{10}\right)$ mass fraction flowing into Seoul from outside to be about $30 \%$, mostly from China.

Energy consumption and resultant emissions of air pollutants from both Seoul and outside might affect the air quality in Seoul. Generally, the concentration of primary

\footnotetext{
* Corresponding author.

Tel.: +82-(0)2-880-2809

E-mail address: jongbaeheo@gmail.com

** Corresponding author.

Tel.: +82-(0)2-3277-2832

E-mail address: yong@ewha.ac.kr
}

air pollutants in Seoul and surrounding areas have decreased since the early 2000s (Kim and Lee, 2018). However, the amount of energy consumption in China has increased rapidly since the 2000s, and primary energy consumption of China has been larger than that of the U.S. since 2009 (BP, 2016). These trends of the energy consumption and emissions are closely related to the air quality management policies. To clarify the effectiveness of air quality management policies, it is important to observe the variations of both the ambient concentrations and emission-related indicators such as energy usage amount at major sources both in Seoul and outside areas, from which air pollutants were moved to Seoul.

PAHs include carbon and hydrogen with a fused ring structure containing at least 2 benzene rings and mainly distributed in the fine particle range (Seinfeld and Pandis, 2016). PAHs are widely distributed in the atmosphere and identified as the suspected carcinogen (Ravindra et al., 2008). The United States Agency for Toxic Substances and Disease Registry (ATSDR) has designated $17 \mathrm{PAH}$ compounds as the priority PAHs based on their toxicological profile (ATSDR, 1995). Except for benzo[j]fluoranthene in the 17 priority PAHs from ATSDR, other compounds are also 
designated as 16 priority PAHs by the United States Environmental Protection Agency (U.S. EPA) and routinely analyzed (Ravindra et al., 2008). In addition, it was reported that heterogeneous reactions of particulate PAHs could change the particle hydrophilicity in cloud processing and thus affect climate change (Marr et al., 2006).

PAHs are mainly formed during incomplete combustion processes of organic matter, such as mobile, industrial, and agricultural sources. Source profiles present unique fractions for all PAH compounds emitted from each of the sources (Ravindra et al., 2008). Therefore, PAHs were widely used to identify the sources using the composition of source emissions (see, for example, Simcik et al., 1999; Lee and Kim, 2007). Moreover, PAHs have been measured, though sporadically, since the 1980s in Seoul (Choi et al., 2016). Thus, it is possible to relate the variation of the PAHs levels in Seoul with the variation of the emissions of air pollutants and related energy usage amount in Seoul and in the Northeast Asia region. In addition, by using long-term data, it is possible to check the consistency of the modeling result for the whole periods since the contributions of the major sources might be changed for each measurement period.

Two receptor models, the U.S. EPA's Chemical Mass Balance (CMB) and Positive Matrix Factorization (PMF) models, have been widely used to study sources of air pollutants of interest. Several CMB modeling studies have been carried out to identify major sources of the observed particulate PAHs in Seoul based on the selected source profiles from China and the U.S. (Lee and Kim, 2007; Kim et al., 2013; Jung et al., 2015). They found out that the observed particulate PAHs have been affected by both emissions in Seoul and the surrounding area and transport from outside such as China and North Korea.

In this study, major sources of the PAHs observed in Seoul were identified with long-term measurement data using the PMF model. The objectives of this study are (1) to identify major sources of PAHs observed in Seoul, (2) to understand trends of the relative and absolute contribution of the major sources, and (3) to check the effectiveness of the air quality management policies in both China and South Korea by considering the variation of the source contribution with the variations of emissions and energy consumptions in Seoul and surrounding areas, especially in China.

\section{MATERIAL AND METHODS}

\section{Measurement Data}

Information on the sampling periods, measured particle size, number of samples, number of analyzed compounds, and references for the data is presented in Table 1. Details on the sampling and analysis of PAHs are given in the references in Table 1. PAH compounds of PM samples were extracted with solvents and the extracts were analyzed using Gas Chromatograph-Mass Spectrometer (GC-MS). Though the particle sizes of the measured samples were different, uncertainty caused by the particle size variation should not be large now that PAHs are mainly distributed in the fine particle range (Seinfeld and Pandis, 2016).

16-17 particulate PAH compounds were analyzed depending on the measurement period. Among the analyzed data, the data for Nap, Ace, Acy, and Flu were not used for modeling since those compounds predominantly exist in the gas phase and, thus, are less reliable. Thus, the data for 12 compounds (Phenanthrane [Phen], Anthracene [Anthr], Fluoranthene [Flt], Pyrene [Pyr], Benzo[a]anthracene [BaA], Chrysene [Chry], Benzo $[b+k]$ fluoranthene $[\mathrm{B}(\mathrm{b}+\mathrm{k}) \mathrm{F}]$, Benzo[e]pyrene [BeP], Benzo[a]pyrene [BaP], Indeno[1,2,3$c d$ pyrene [Ind], Dibenz $[a, h]$ anthracene [DahA], Benzo[ghi]perylene [BghiP]) were used for the modeling of the whole periods. These compounds are classified into three group with the number of benzene rings. Low molecular weight PAHs are indicating PAHs with 3, 4-rings (Phen, Anthr, Flt, Pyr, BaA, Chry, B[b+k]F). Moreover, medium MW PAHs and high MW PAHs are with 5-rings (BeP, BaP, Ind, DahA) and 6-rings (BghiP), respectively. Table S1 summarizes the PAHs compounds used for this study. However, since in a sizable fraction of the concentration of DahA in the data set were below the detection limit or missing (over 50\%), its data were used in the modeling for the first and second periods only.

As shown in Table S1, the average concentrations of the sum of 12 PAHs compounds decreased from $24.6 \mathrm{ng} \mathrm{m}^{-3}$ in 2002-2003 to $7.5 \mathrm{ng} \mathrm{m}^{-3}$ in 2012-2013, about $70 \%$ decrease during 10 years. Thus, it is necessary to verify the major sources and the variation of the emissions from them.

For the sampling days, 3-day backward trajectories at the arriving height of $1500 \mathrm{~m}$ were calculated using Hybrid Single-Particle Lagrangian Integrated Trajectory (HYSPLIT4) model (Stein et al., 2015) coupled with GDAS $\left(1^{\circ} \times 1^{\circ}\right)$

Table 1. Information of the particulate PAHs measurement in Seoul in each period.

\begin{tabular}{|c|c|c|c|c|c|}
\hline Period & $\begin{array}{l}\text { Particle } \\
\text { size }\end{array}$ & $\begin{array}{l}\text { No. of } \\
\text { samples }\end{array}$ & $\begin{array}{l}\text { No. of } \\
\text { compounds }\end{array}$ & Sampling site & Reference \\
\hline $\begin{array}{l}\text { Aug. 2002-Dec. } 2003 \\
\text { (17 months) }\end{array}$ & TSP & 68 & 17 & $\begin{array}{l}\text { Ewha Womans University } \\
\left(37^{\circ} 33^{\prime} \mathrm{N}, 126^{\circ} 56^{\prime} \mathrm{E}\right)\end{array}$ & Lee et al. (2011) \\
\hline $\begin{array}{l}\text { Aug. 2006-Aug. } 2007 \\
\text { (13 months) }\end{array}$ & $\mathrm{PM}_{10}$ & 73 & 17 & $\begin{array}{l}\text { Seoul national University } \\
\left(37^{\circ} 27^{\prime} \mathrm{N}, 126^{\circ} 57^{\prime} \mathrm{E}\right)\end{array}$ & Hong et al. (2009) \\
\hline $\begin{array}{l}\text { Apr. 2010-Apr. } 2011 \\
\text { (13 months) }\end{array}$ & $\mathrm{PM}_{10}$ & 52 & 16 & $\begin{array}{l}\text { Seoul national University } \\
\left(37^{\circ} 27^{\prime} \mathrm{N}, 126^{\circ} 57^{\prime} \mathrm{E}\right) \text {. }\end{array}$ & Choi et al. (2016) \\
\hline $\begin{array}{l}\text { Oct. 2012-Sep. } 2013 \\
\text { (12 months) }\end{array}$ & $\mathrm{PM}_{2.5}$ & 114 & 16 & $\begin{array}{l}\text { Korea Institute of Science and } \\
\text { Technology } \\
\left(37^{\circ} 60^{\prime} \mathrm{N}, 127^{\circ} 05^{\prime} \mathrm{E}\right)\end{array}$ & Kim et al. (2016a) \\
\hline
\end{tabular}


developed in the National Oceanic and Atmospheric Administration (NOAA). Most trajectories had passed over north China, northeast China, or North Korea before arriving at Seoul (Kim et al., 2013, 2016c) during the sampling days. For example, during the 2002-2003 sampling period, more than $80 \%$ of the trajectories were from either north China, or northeast China and North Korea (Kim et al., 2013).

\section{PMF Modeling}

The U.S. EPA PMF v. 5.0 (Norris et al., 2014) was used in this study. PMF is a multivariate factor analysis tool that decomposes a matrix of speciated sample data into two matrices, source profile and source contribution.

According to Paatero (1997), fundamental equations about PMF can be presented with the definitions of matrices. The "residual matrix" $E$, the difference between measurement concentration $\left(X_{i j}\right)$ and modeled concentration $\left(Y_{i j}\right)$, is defined as a function of the factors $G$ and $F$, as described in Eq. (1), where $X$ is a matrix of observed data and $n \times m$ dimensions where $G$ is the unknown left hand factor matrix (scores) of $n \times p$ dimensions, and $F$ is the unknown right hand factor matrix (loadings) of $p \times m$ dimensions (Paatero and Tapper, 1994):

$$
E_{i j}=X_{i j}-Y_{i j}=X_{i j}-\sum_{h=1}^{p} G_{i h} F_{h j} \quad(i=1, \ldots, \mathrm{m}, j=1, \ldots, \mathrm{n})
$$

The "object function" $Q$, to be minimized, is defined as a function of the factors $G$ and $F$, as in Eq. (2):

$$
Q(E)=\sum_{i=1}^{m} \sum_{j=1}^{n}\left(E_{i j} / \sigma_{i j}\right)^{2}
$$

The values $\sigma_{i j}$ are the standard deviation of the observed value $X_{i j}$. The task of the non-negatively constrained weighted factor analysis is: Minimize $Q(E)$ with respect to $G$ and $F$ under the constraint that all or some of the elements of $G$ and $F$ are constrained to non-negative values (Paatero, 1997). More details on PMF were described in Paatero and Tapper (1994) and Norris et al. (2014).

In this study, the analyzed concentration values were used for the measurement data, and the error fractions and $1 / 2$ of the method detection limit (MDL) values were used as the overall uncertainty assigned to each observation with higher concentration than MDL (Norris et al., 2014), as:

uncertainty $=$

$\sqrt{\left.(\text { error fraction } \times \text { concentration })^{2}+\left(\frac{1}{2} \times \mathrm{MDL}\right)^{2}\right)}$

The error fraction for the ambient data was set as $15 \%$ (the variation of the measurement) of the concentration for individual PAH compounds since the uncertainty for the MDL values of individual PAH compounds were small (Lee and Kim, 2007). Concentrations below the MDL were replaced by half of the MDL and their overall uncertainties were set at 5/6 of the MDL. Missing values were replaced by the median of the measured values and associated uncertainties were set at 4 times of the median.

Optimal number of factors was determined by checking the maximum individual column mean (IM), the maximum individual column standard deviation (IS) values following the approach from Lee et al. (1999). Displacement (DISP), bootstrap (BS) parameter values from Paatero et al. (2014) and Brown et al. (2015) were also considered to set the optimal number of factors to reduce the estimation errors. IM and IS are the indicators to identify the species having the least fit and the most imprecise fit (Lee et al., 1999). And they can also be used to identify the number of factors in the PMF. When the number of factors increases to a critical value, IM and IS will experience stability after a drastic drop.

DISP intervals include effects of random errors and partially include effects of rotational ambiguity. For DISP, focus is on the number of swaps at the lowest $\mathrm{dQ}^{\max }$ level and the percent change in Q (\%dQ) (Brown et al., 2015). We focused on the \%dQ of the DISP and acceptable range of $\% d Q$ was set as 0.1 , following Paatero et al. (2014). The U.S. EPA PMF performs BS by randomly selecting nonoverlapping blocks of consecutive samples (block size is suggested by the software) and creating a new input data file of the selected samples, with the same dimensions as the original data set. The PMF is then run on the new resampled data set, and each BS factor is mapped to a base run factor by comparing factors' contributions for those samples included in the resampled data set (Brown et al., 2015).

The result of the PMF model has uncertainty because the degree of the contribution from a major source might be changed during the period. Thus, the model was applied to two sets of data. First, the whole measurement results from 2002 to 2013 were used as one data set to estimate major factors throughout the whole periods. Then the measurement result at each sampling period was modeled separately.

\section{RESULTS AND DISCUSSIONS}

\section{Identification of Factors}

Variance of the IM, IS, DISP, and BS parameter values for the cases of 4-7 factors are presented in Table 2. IM and IS values dropped twice when the number of factors is over 5 and 7, respectively. DISP results for the changes of $\mathrm{dQ}$ are less than the acceptable range $(<0.1)$ for all cases. When the number of factor is equal to or higher than 5 , BS values becomes smaller with the increasing number of factors. Thus, optimal number of factors is determined as 5 .

Moreover, the relationship between the observed and estimated concentrations for total PAHs was quite good (y $\left.=0.9538 \mathrm{x}+0.3478, \mathrm{r}^{2}=0.9836, \mathrm{n}=307\right)$. It means that almost all the observed PAHs were well reproduced by the PMF modeling result with 5 factors.

Lee and Kim (2007) reported the CMB modeling result with the data of the first period of this study and Jung et al. (2015) applied the CMB model to the data of the first and 
Table 2. Variations of the performance parameters, IM (the maximum individual column mean), IS (the maximum individual column standard deviation), DISP (Displacement analyze, \%dQ), and BS (Bootstrap analyze, \%) with the estimated number of factors.

\begin{tabular}{lllll}
\hline Number of factors & IM & IS & DISP & BS \\
\hline 4 & 0.49 & 1.70 & 0.000 & 96 \\
5 & 0.33 & 1.50 & 0.005 & 98 \\
6 & 0.32 & 1.40 & 0.001 & 92 \\
7 & 0.19 & 1.10 & 0.005 & 90 \\
\hline
\end{tabular}

second periods of this study. They estimated that the impacts from the emissions of PAHs from coal usage in China for coke oven and residential usage were significant for the observed PAHs level during these two periods. They both identified 7 major emission sources based on the emission data in Seoul and Northeast Asia. However, since the contributions from 2 factors were minor, natural gas combustion and coal-fired power plant for both periods, they also concluded that these 5 factors were major factors.

Fig. 1 presents the source profiles of the 5 identified factors for the whole measurement periods from 2002 to 2013. For the modeling results of each period (Fig. S1), 5 factors were also identified except for the last period. In addition, the factors obtained from the modeling of each period (Fig. S1) were similar with that of the whole periods shown in Fig. 1. It suggested the result of major factors for the whole periods be a reasonable one. Here, we defined the profiles estimated from separate modeling result with different measurement periods to be similar if the characteristics of the profiles are similar and the seasonal trends of the relative contributions were comparable. In the modeling for the last period, 4 factors were identified and the factor profile designated as Factor 1 (coke oven coal usage) for the whole periods was not found. The temporal variation of the relative contributions of each factor obtained from the PMF modeling for the whole periods are shown in Fig. S2.

\section{Coal Usage}

Coal consumption has been restricted since 1991 and banned since 2003 in Seoul proper and restricted in the Seoul Metropolitan Area (SMA) since 2005 (Kim, 2006). Also, emission of the PAHs from coal-fired power plant was small due to high combustion efficiency and strict emission standard against particles in Korea (Lee and Kim, 2007). In addition, the steelworks in which coke ovens were operated were located on southern parts of Korea during the measurement periods and since the prevailing wind were the westerlies and north westerlies, impacts of the emission from Korea should be minor for coal combustion factors (Jung et al., 2015). Thus, the emission sources, identified as coal usage might be from outside of Seoul and Korea, probably from China as reported from Lee and Kim (2007) and Jung et al. (2015).

The first and second factors were identified as emission sources from coal usage for coke oven and residential usage, respectively, based on the characteristics of the profiles. As shown in Fig. 1(a), contributions of medium MW PAHs were larger than low and high MW PAHs in the profile, typical characteristics of coal combustion. Also the estimated profile shows similar characteristics of the profiles of coal usage in coke oven in China (Yang et al., 2002). Also, as shown in Fig. S2(a), the relative contribution of the first factor, coke oven coal usage, showed no apparent seasonal variation since coke oven operation has been less dependent on season comparing to other sources. It also supported that the first factor was coke oven coal usage. The second factor was identified as coal combustion in residential usage. As shown in Fig. 1(b), the profile was similar with the residential coal combustion in China (Zheng et al., 2005; Yan et al., 2017). Predominant species (i.e., Phen, Flt, and Pyr) in this factor have been described as coal combustion source markers in the previous studies (Harrison et al., 1996; Simcik et al., 1999; Sofowote et al., 2011). The relative contributions were also identified as residential coal usage showed high contributions in winter as shown in Fig. S2(b), supporting this factor being residential usage for heating. As explained before, since the major emission sources identifies as coal usage were mainly from China, the estimated profiles were compared with the reported profiles.

Since coal-related factors were considered as the mainly affected from regional contributors, backward trajectories were shown to verify the regional impact for the sampling days showing the highest contributions in coal usages, both coke oven and residential coal combustion (Nov. 11, Dec. 6, 21, and 27 in 2006). Red trajectories in Fig. 2 shows dominant direction from north China where the consumptions of coal for coke oven and residential heating have been known to be large in China (Shen, 2016), passing through the Yellow Sea before arriving in Seoul. It suggested that the impact from the sources in north China be the dominant one for these 4 sampling days, partially supporting these factors might be related to coal usages.

The relative and absolute contribution of the coke oven coal usage has declined during the whole periods as shown in Fig. 3, in which the variations of the relative and absolute contribution of the 5 factors for the modeling of whole periods were shown. These decreasing trends of not only the relative contribution but also absolute contribution of coke oven were closely related to variation of the PAH emission from coke oven and coal usage in China.

To further understand the trends, the temporal trends of the total coal usage in coke oven and the ratio of coke oven to the total coal consumption in China are investigated. Though the amount of the coal usage in coke oven increased during the whole study periods from 46,058 kt in 2002 to $141,654 \mathrm{kt}$ in 2013 , the ratio of the coke oven usage to the total coal 


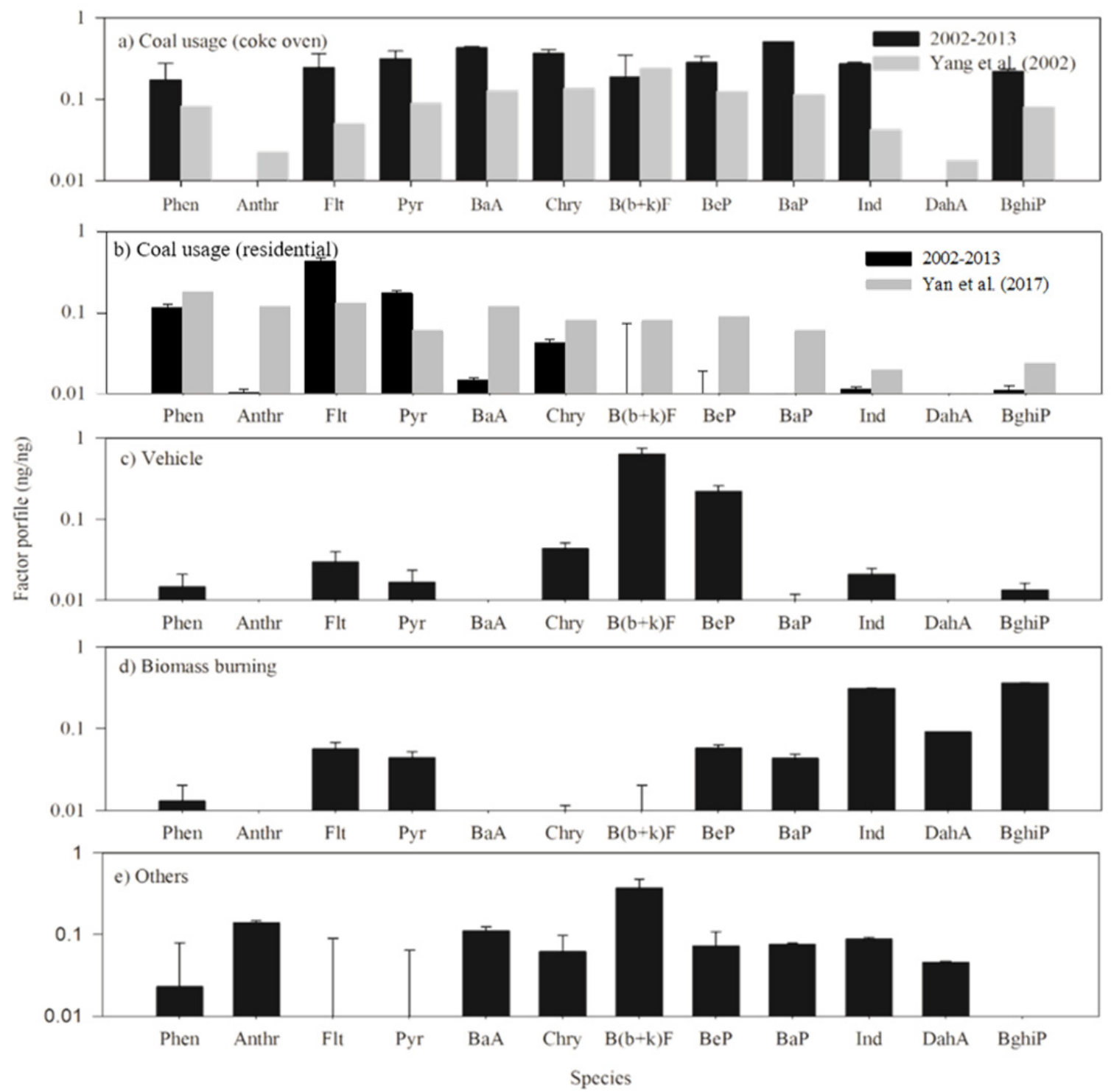

Fig. 1. Source profiles of each factors of the modeling results for the whole periods (ng ng $\left.{ }^{-1}\right)$.

consumption in China after 2005 was around $4 \%$ without large variation (IEA, 2016). It showed that the amount of coke oven coal usage has continuously increased following the total coal consumption. However, the PAHs emission from coke oven coal usage showed continuous decreasing trend. The contribution of PAH emission from coke oven coal usage in 2003 and 2004 was about $16 \%$ (Xu et al., 2006) and 14\% (Zhang and Tao, 2009) at China, respectively. And it was ranked second or third among the PAH emission sources in China (Zhang and Tao, 2009). However, Shen et al. (2013) showed that emission amount of the 16 PAHs from coke production was dramatically decreased since the late 1990s. The decreasing trend was related with the elimination of beehive coke oven in China and installation of control equipment.

Coking industry can be divided into mechanical coking and beehive coking. Beehive coking which has been seldom seen in developed countries is found to be associated with high levels of PAH emissions because of the poor design of coke oven and lack of control devices (Shen, 2016). Since control devices with higher PM removal efficiency can remove PAHs more effectively (U.S. EPA, 1998), PM control devices were installed in most large coke plants with mechanized coking facilities. On the other hand, few were installed in small plants with indigenous coking facilities (Lei et al., 2011). Though beehive coking had spread without restriction in China in the 1990s (Zhang et al., 2007), the coal law enacted in the middle 1990s prohibited beehive coking on a national scale in order to reduce beehive coking with large amount of emissions (Standing Committee of the National People's Congress, 1996). Shen et al. (2016) shows the real ratio of beehive coke production to total coke production in China and its ratio was drastically decreased during the period and it became 0 in 2011. This change in China might be the reason for the decreasing trend of relative and absolute contribution of this factor to the particulate PAHs emission. For example, estimated Emission Factor (EF) for coke oven decreased from $49 \%$ 


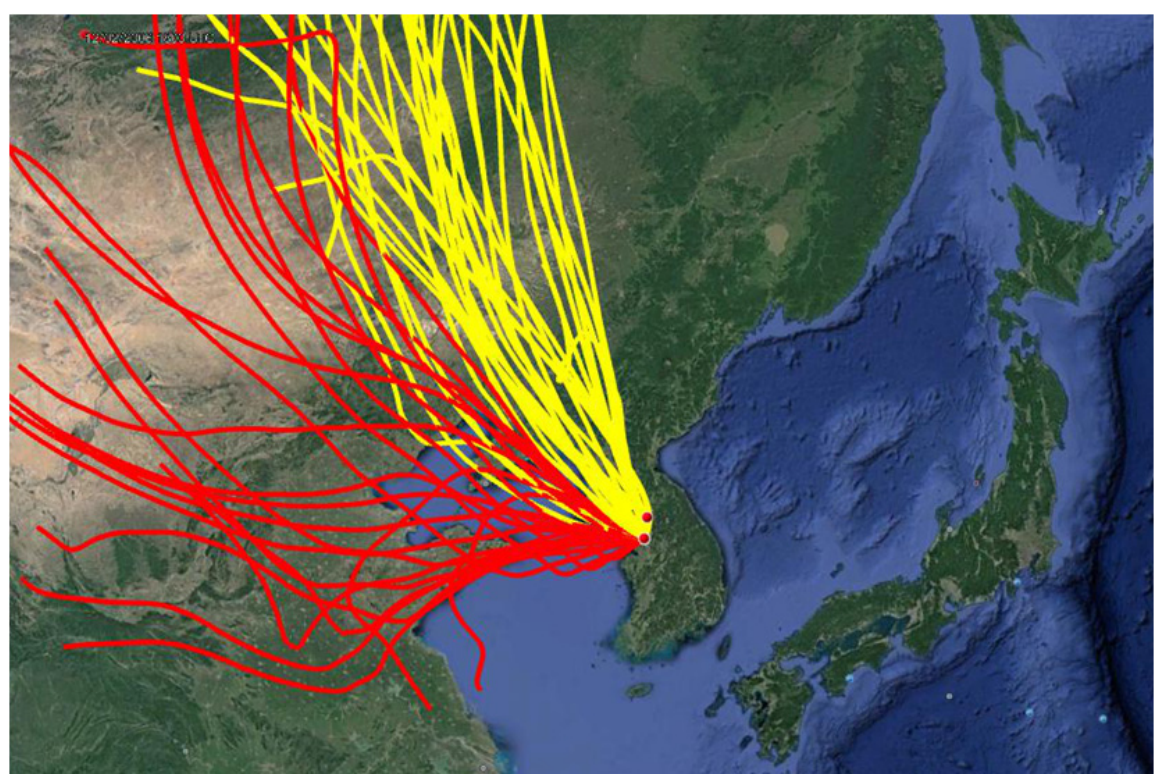

Fig. 2. Three days backward trajectory analysis results for the 4 days with high contribution of coke oven coal usage and residential coal combustion (red) and biomass burning (yellow).

in 1995 to $18 \%$ in 2005 , resulting in a decrease in PM EFs as well (Lei et al., 2011) and Shen et al. (2013) also shown that trends until 2008. Moreover, in Zhao et al. (2013), $\mathrm{PM}_{10}$ emissions from coke oven also show decreasing trend until 2010. It also explained, though partly, that the PMF modeling for the period of 2012-2013 gave only 4 factors without the coke oven factor instead of 5 for the optimal result (Fig. S1).

The variation of the relative and absolute contribution of the second factor, designated as residential coal usage during the whole periods is also presented in Fig. 3. Relative contribution of the residential coal usage decreased till 2010-2011 period and slightly increased in 2012-2013. According to Shen (2016), after continuous increases in PAH emissions, the PAH emissions from residential sources in developing countries, such as China and India, started to decrease slowly around 1995 . The main reasons for this decrease were replacement of residential coal cooking stoves with natural gas stoves in large and median cities (NBS, 2016) and dissemination of improved biomass cook stoves in rural households (Barnes et al., 1994). Thus, the decreasing trend of the relative contribution of this factor might be related to the change of the coal consumption to total energy consumption ratio for residential usage in China.

Fig. 4 shows coal and natural gas consumption for residential usage in China. Except the increase between 2004 and 2007, there was no apparent change in coal consumption amount. Meanwhile, the natural gas consumption has dramatically increased after 2000. Due to these trends, the ratio of the coal consumption to the total energy consumption for residential usage has decreased and the ratio of the natural gas consumption to coal combustion for the residential usage has increased. Also, the emission amount of air pollutants from coal combustion has decreased due to stricter emission standard and application of combustion equipment with higher combustion efficiency in China (Chang et al., 2016; Zheng et al., 2018). These trends suggested the decreasing portion of the residential coal usage effect on the decreasing trend of the relative contribution of the factor. However, it is not clear why the contribution of this factor has slightly increased in the last period, 2012-2013.

\section{Vehicles}

The profile of the third factor showed that Chry, $\mathrm{B}(\mathrm{b}+\mathrm{k}) \mathrm{F}, \mathrm{BeP}$, and $\mathrm{BaP}$ were the major compounds among the analyzed compounds. Chry and $\mathrm{B}(\mathrm{b}+\mathrm{k}) \mathrm{F}$ were mainly attributed to diesel motor vehicle emissions and $\mathrm{BaP}$ was attributed to gasoline and diesel motor vehicle emissions (Harrison et al., 1996; Lee et al., 2004; Zhang et al., 2012). Thus, the third factor was identified as vehicular sources.

The trends of the relative and absolute contribution of the third factor identified as vehicular source are shown in Fig. 3. The relative contribution increased before the last period and decreased slightly after 2010-2011. However, the absolute contribution has been increased continuously. Possible reasons for the decreased relative contribution of the last period might be decreased emissions from vehicles in both Korea and impact of the other factors' contributions.

First, the number of registered vehicles at Korea in 2013 was 19.40 million, about 1.5 times higher than that in 2000, 12.06 million (MOLIT, 2016). This drastic increasing trend of number of registered vehicles can explain the increasing contribution of whole period. However, in Korea, the emission amount from vehicular sources has continuously decreased during the whole measurement period, while the number of registered vehicles has increased. For diesel vehicle, Euro IV was applied and Diesel Particulate Filter (DPF) was installed to reduce the emissions of particulate matters in 2006 and Euro V was applied in 2009. In 2006, emission standard for gasoline vehicle was also set as Ultra-Low Emission Vehicle 2 (ULEV2). Thus, both 


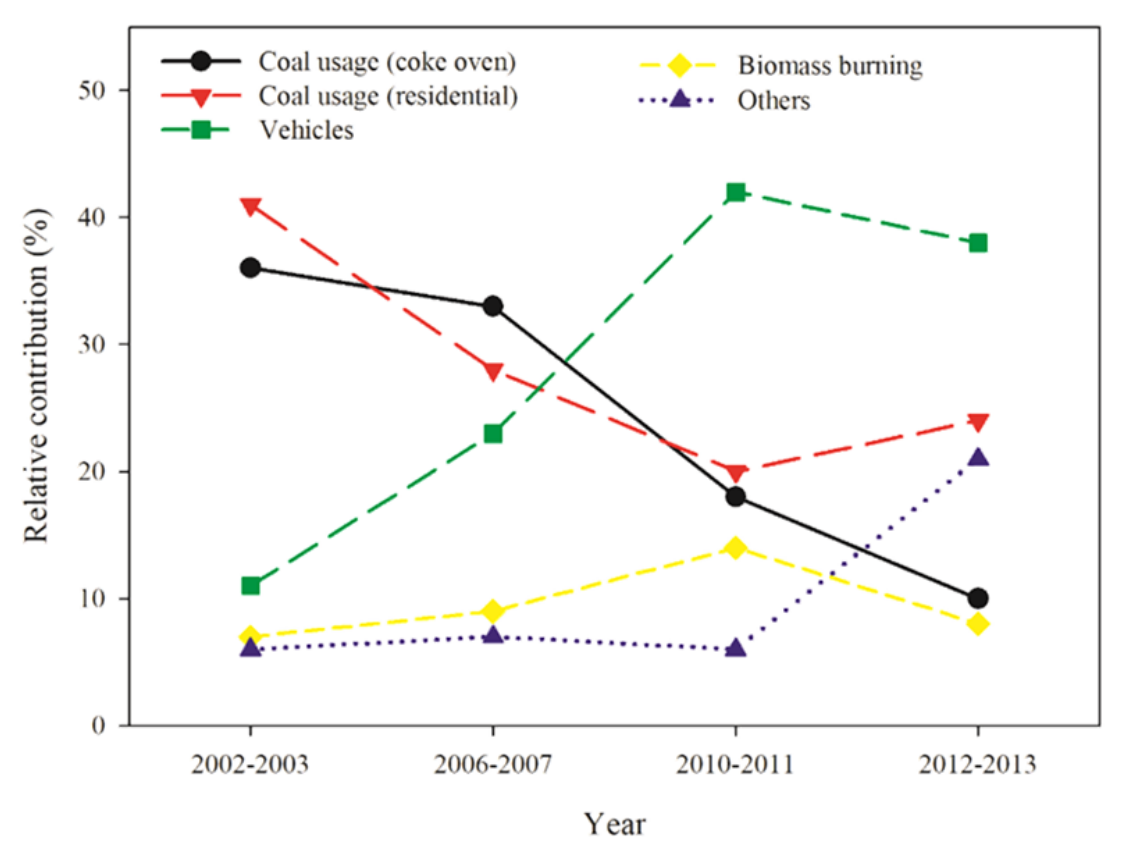

(a) Relative contributions for each factor (\%)

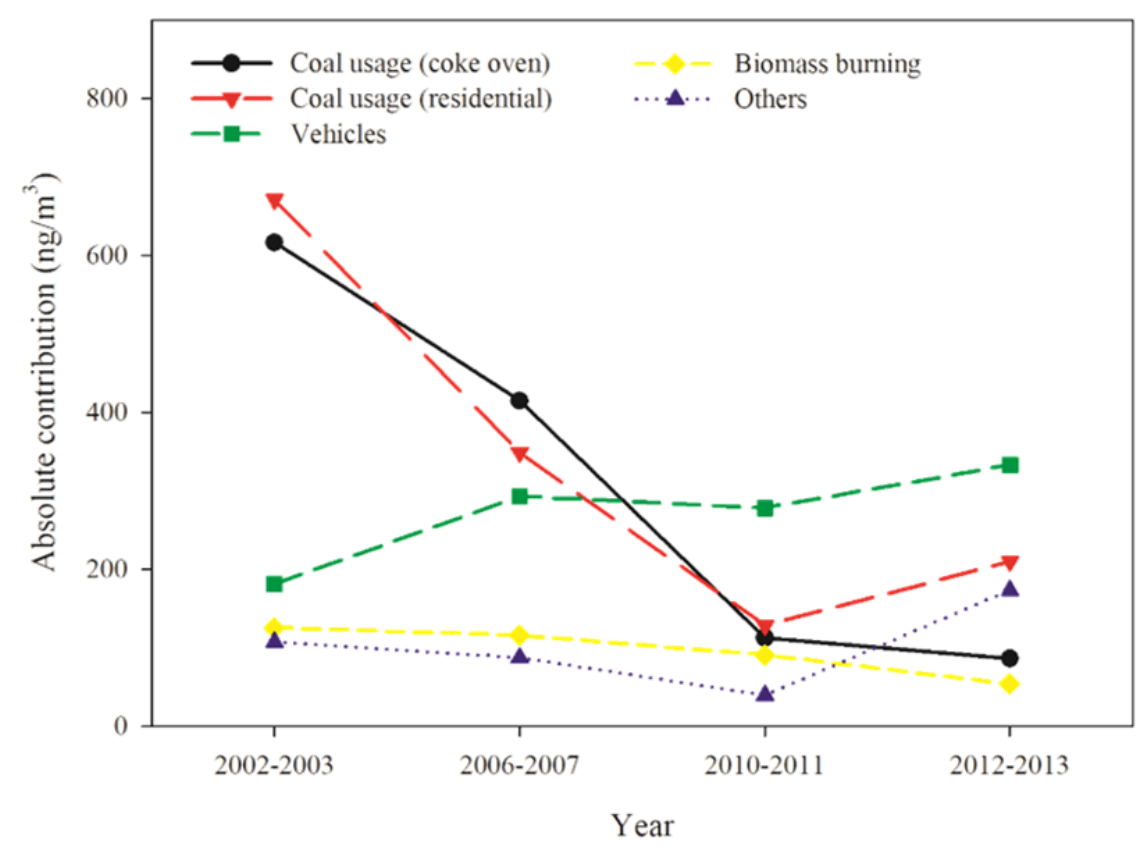

(b) Absolute contribution for each factor $\left(\mathrm{ng} \mathrm{m}^{-3}\right)$

Fig. 3. Variation of the relative and absolute contribution of five factors to the observed PAHs.

$\mathrm{PM}$ and $\mathrm{NO}_{\mathrm{x}}$ emission amount have been reduced since 2006 (NIER, 2014). These emission trends have affected on the relative contribution results of the vehicle source.

It looked reasonable that after 2011 the emission from vehicles decreased in Korea. Thus, the slightly decreased relative contribution of the vehicular emission after 2011 could be explained with the emission reduction in Korea. However, the trend of the absolute contribution of vehicular source keep increasing for the periods. So, the emission trend of PAHs from vehicles in Korea cannot fully explain the trend of the absolute contribution of this contributor.
To figure out the impact of local emission more clearly, we verified daily contribution of vehicular emission source (Fig. S3(a)). In the first period (2002-2003), this factor showed higher contribution in summer. However, in the second and third periods, it showed no apparent seasonal trend, though high contribution was observed on Nov. 6, 2010. The number of haze event from March to June in 2003 was significantly higher compared with other times (KMA, 2016). In addition, on Nov. 6, 2010, a haze event was observed and the average wind speed was $2.0 \mathrm{~m} \mathrm{~s}^{-1}$, lower than the monthly average in November in 2010. 


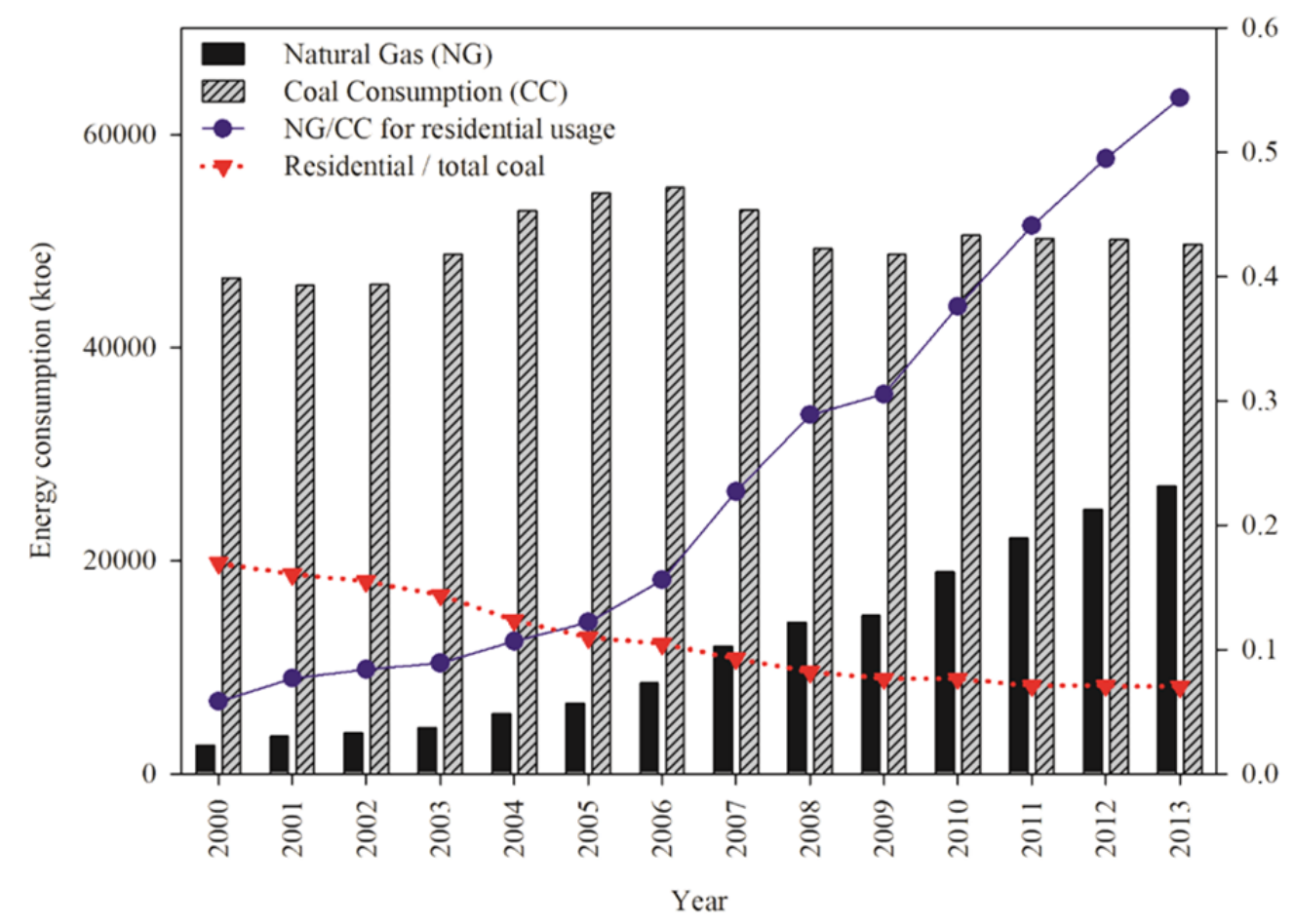

Fig. 4. Variation of the consumption of coal and natural gas for residential sector (ktoe) in China (IEA, 2016).

These conditions suggested that the stable condition of the atmosphere and haze event affected the accumulation of PAHs from local vehicular sources for the first period and Nov. 6, 2010. It suggested that the local emission from vehicular sources has largely affected on the concentration of PAHs in Seoul, Korea. Moreover, for the last period, the relative contribution of this factor drastically decreased on the fall 2013. It might be affected by the contribution of the others source. The details of the others source will be discussed in Section 3.5.

\section{Biomass Burning}

The fourth factor was identified as biomass burning, because BghiP, Ind, $\mathrm{BaP}$, and $\mathrm{BeP}$ consisted of a significant fraction among the analyzed compounds. These compounds were known as predominantly emitted from soft wood burning samples (Bari et al., 2009). According to the previous studies (Lee and Kim, 2007; Kim et al., 2013), a sizable fraction of particulate PAHs in the ambient air in Seoul were affected by biomass burning emissions from both China and North Korea, but more prominently from North Korea. Kim et al. (2016a) have applied a receptor model, Solver for Mixture Problem (SMP) model, for the organic compounds in $\mathrm{PM}_{2.5}$ between October 2012 and September 2013 in Seoul. They could separate the contribution from local biomass burning (5\%) to the transported biomass burnings (8\%). Thus, the estimated biomass burning PAHs in the ambient air in Seoul were emitted from both inside and outside of the SMA.

Biomass burning occurred both naturally and anthropogenically. Comparing with other sources, the seasonal variation of the contribution from biomass burning was distinct, high in spring as shown in Fig. S3(b). Natural biomass burning in Northeast Asia was mostly forest fire and usually occurred in springtime (In et al., 2009). Anthropogenic activities consisted of open burning mostly after harvest (fall) and before seeding (late winter to early spring) and residential fuels (year-round but most significant in winter) (Lee and Kim, 2007).

On Aug. 16-17, 2013, high contribution from biomass burning factor was estimated, which was an unusual event since biomass burning contribution was generally not high in summer. Thus, 3-day backward trajectories for these days were also examined. Interestingly, the air parcels were passed through Shanghai, China and the Yellow Sea before arriving in Seoul in these days as shown in Fig. 5(a). It turned out that during this period, fires were observed at the area around Shanghai by Fires and Thermal Anomalies with Worldview tool provided from Earth Observing System Data and Information System (EOSDIS) of National Aeronautics and Space Administration (NASA) (Fig. 5(b)). It demonstrated that the reliability of the modeling result. The variation of the relative contribution of biomass burning factor was shown in Fig. S3(b). Though the relative contribution in 2010-2011 was the highest among the periods, there was no significant change during the whole periods. Relative contribution of biomass burning during the whole periods was around $10 \%$, similar proportion of biomass burning in Seoul from previous studies (Lee and Kim, 2007; Heo et al., 2009).

To check the major emission areas for the fourth factor, assumed to be biomass burning, 3-day backward trajectories were estimated for the 4 sampling days of high contributions of the fourth factor (Mar. 9 and 30 and Apr. 16 in 2011 and Jan. 17 in 2013) as shown as yellow lines in Fig. 2. According to the backward trajectories, air parcels were passed 


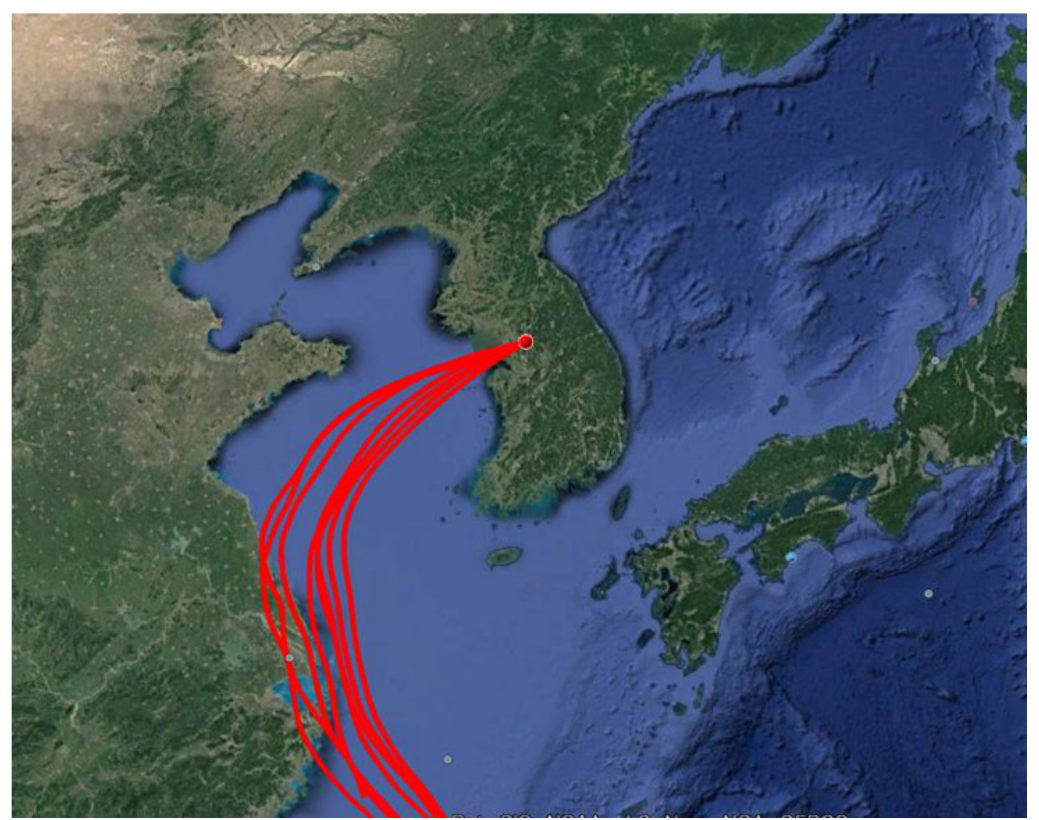

(a) Relative contributions for each factor $(\%)$

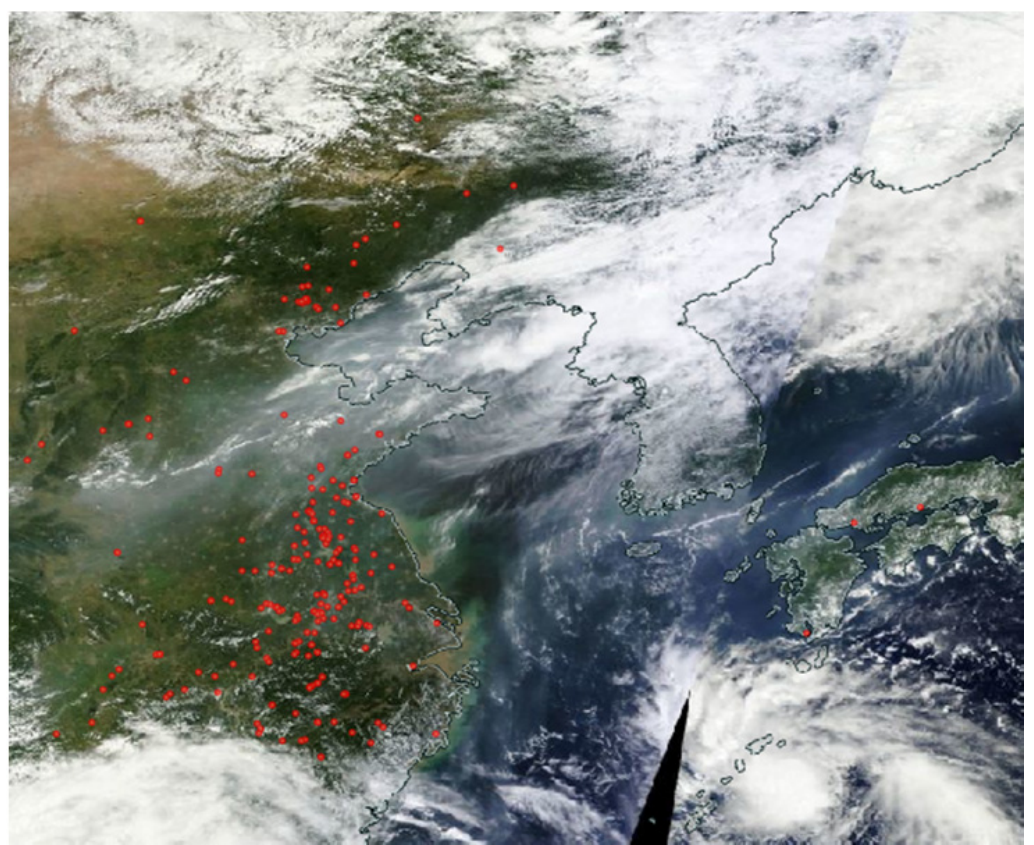

(b) Absolute contribution for each factor $\left(\mathrm{ng} \mathrm{m}^{-3}\right)$

Fig. 5. (a) Three days backward trajectories for Aug. 16 and 17, 2013 and (b) thermal anomalies with worldview tool for Aug. 17, 2013 from NASA's Earth Observing System Data and Information System (EOSDIS). The red color marked at near Shanghai meant that fires and thermal anomalies were observed with Moderate Resolution Imaging Spectroradiometer (MODIS).

through north China and North Korea before arriving in Seoul in contrast to the backward trajectories for the coal usage as shown in Fig. 2. As explained in Kim et al. (2013), emissions of PAHs from coal combustion and biomass burning were higher in north China than northeast China. Thus, it suggested that impact of transport from North Korea to Seoul was considerable in case of biomass burning. The impact of the biomass burning emission from North Korea to Seoul was estimated in the previous studies (Lee and
Kim, 2007; Kim et al., 2013). Residential biomass burning represented the highest $\mathrm{PAH}$ contribution among all combustion sources in Seoul for the first measurement period, 2002-2003.

In developing countries, solid biomass including wood, straw, and dung cakes are widely used for cooking and heating because they are cheaper and much easier to access than other fuels (Shen, 2016). In North Korea, wood and biomass burning was the second largest energy type as 20- 
$30 \%$ among the energy supply types during the whole periods (von Hippel and Hayes, 2012). Alternative energy sources were required in addition to the decreased energy consumption and that was biomass due to the limitation of supply of coal and oil in North Korea (Kim et al., 2013). In addition, according to the report of International Energy Agency (IEA, 2016), while the primary energy consumption was drastically decreased from $677,693 \mathrm{TJ}$ in 2010 to 497,027 TJ in 2011, the solid biofuel has kept high consumption level as 31,141 TJ and 31,292 TJ in 2010 and 2011 , respectively. The amount of the consumption of primary solid biofuels has increased from 29,663 TJ in 2000 to $31,512 \mathrm{TJ}$ in 2013 . This change was the combined result of continued reduction in fuel demand in the industrial sector, slow rising of biomass fuel usage for cooking and other biomass fuels in the residential and other sectors, and reductions in the usage of other residential fuels that were not as severe as the reductions experienced in the industrial sector (von Hippel and Hayes, 2012).

Thus, the non-decreasing biomass burning activities in North Korea might impact on the increased relative contribution of biomass burning until 2010-2011. However, absolute contribution of the PAHs emitted from this contributor also do not show drastic changes during the periods. Thus, in the last period, the reason for slightly decreasing trend of the relative contribution might be affected by high fraction of other factors in the last period.

\section{Others Factor and Uncertainty}

The last factor (fifth factor) was left as "other factors" since its uncertain characteristics and it seems that it contains combination of other minor sources (for example, natural gas combustion and coal-fired power plants), and uncertainties of the modeling results. Also, the large difference between the results of two modeling approaches was observed for the last period. According to the temporal variation of the relative contribution of this factor, it shows small contribution from the first to third periods with high contribution only in the last period.

Moreover, the scatter plot of observed and estimated concentrations of total PAHs for the last period only and for the whole periods without the last period were investigated. The ratio of estimated to observed concentrations without the last period was closer to unity $(\mathrm{y}=0.9592 \mathrm{x}+0.1599$, $\left.\mathrm{r}^{2}=0.9884\right)$ than that with the last period $(\mathrm{y}=0.9205 \mathrm{x}+$ $\left.0.7457, \mathrm{r}^{2}=0.9113\right)$. In other words, estimated concentration without the last period performed better than that with the last period. Thus, it also suggested the last period might not represent the sampling period well. Thus, it might reflect the characteristics of the sampling site or sampling period. One possibility is that the emission characteristics of the last period (2012-2013) might be different from other periods. Another possibility is the change of the sampling frequency. During the last period samples were collected for about a month in each season while in other periods samples were collected yearly. It might affect the model's result.

This factor might affect the other factors' contribution trends, such as a decrease in biomass burning and the difference between two methodologies in vehicular sources.
One possible contributor for the last factor is soil dust. Comparing with the results from Kim et al. (2016a) for the last period, street dust presents the similar seasonal trend of relative contribution, low in winter. In this study, since there is no factor related with street dust, the last factor might be the factor related with it.

There is additional uncertainty caused by the emission inventories. To clarify the reasons of relative contributions' trends for each factor, the emissions should be considered during the period. The emission inventories were developed using a bottom-up approach based on activity intensity and emission factors as multiplied activity data of the source $(A)$ and emission factors $(E F)$. $A$ reflects the amount of fuel combusted, for instance, the industrial production levels as for industrial sector and the distances traveled or the oil consumed for transportation, respectively. $E F$ is defined as emission per unit activity, which depends significantly on the compound and the source category (Shen, 2016). Since the disparity of the $E F$ caused by technical differences among countries and development, there might be uncertainty of emission amounts. The uncertainty of the $E F$ is limitation of the emission inventories.

\section{SUMMARY}

To verify and quantify the trend of contributions from major sources to the observed particulate PAHs in Seoul, the PMF model was applied to long-term measurement data of PAHs in the ambient air. By evaluating 4 performance evaluation parameters, 5 was determined to be the optimal number of factors, which was supported by the ratio of the estimated to the observed concentrations (almost unity). Good agreement between the results from two methodologies, one using data for all of the periods and the other using different data sets for each period, was found, suggesting that the PMF modeling results are highly reliable, except concerning the last factor.

Based on the backward trajectories and comparisons with PAH profiles from China and with seasonal trends in relative contributions, the first and second factors were identified as coal usage for coke ovens and residences, respectively. Regulations on coke ovens in China and the ratio of coke to coal combustion may explain the long-term decreasing trend of these factors' contributions. Reduced residential coal consumption, due to a drastic increase in the consumption of natural gas, also corroborates this trend.

The third factor, identified as vehicular emission, displayed significant effects from local emissions, based on statistics and analyses of specific episodes. The fourth factor, biomass burning, contributed a high percentage to the total amount of PAHs during spring and special events, indicating that such emissions typically originate in forest fires and other events occurring outside the SMA. Backward trajectories for the 4 days exhibiting high relative contributions from biomass burning also supported this conclusion.

The fifth factor was left as "other factors" due to its ambiguous characteristics and the large difference between the results from the two methodologies, especially for the last period. Since this factor potentially influenced the other 
factors' relative contributions, we considered the uncertainties of the former in suggesting reasons for variations in the latter.

Overall, the modeling results reflected long-term trends in both energy consumption and emissions, indicating that the amount of particulate PAHs has been reduced in various sectors due to air quality management policies in both South Korea and China.

\section{ACKNOWLEDGMENTS}

This work was supported by the National Research Foundation of Korea (NRF) grant funded by the Korea government (MSIP) (NRF-2017R1A2B4006760).

\section{SUPPLEMENTARY MATERIAL}

Supplementary data associated with this article can be found in the online version at http://www.aaqr.org.

\section{REFERENCES}

ATSDR (Agency for Toxic Substances and Disease Registry) (1995). Toxicological profile for polycyclic aromatic hydrocarbons (PAHs). US Department of Health and Human Services, Public Health Service. Atlanta, GA. http://www.atsdr.cdc.gov/toxprofiles/tp69.htmlS.

Barnes, D.F., Openshaw, K., Smith, K.R. and van der Plas, R. (1994). What makes people cook with improved biomass stoves? A comparative international review of stove programs. The World Bank, Washington, USA.

BP (British Petroleum) (2016). http://www.bp.com/en/glo bal/corporate/energy-economics/statistical-review-of-wo rld-energy/primary-energy.html, Last Access: 23 June 2016.

Brown, S.G., Eberly, S., Paatero, P. and Norris, G.A. (2015). Methods for estimating uncertainty in PMF solutions: Examples with ambient air and water quality data and guidance on reporting PMF results. Sci. Total Environ. 518-519: 626-635.

Chang, S., Zhuo, J., Meng S., Qin, S. and Yao, Q. (2016). Clean coal technologies in China: Current status and future perspectives. Engineering 447-459

Choi, N.R., Lee, S.P., Lee, J.Y., Jung, C.H. and Kim, Y.P. (2016). Speciation and source identification of organic compounds in $\mathrm{PM}_{10}$ over Seoul, South Korea. Chemosphere 144: 1589-1596.

Harrison, R.M., Smith, D. and Luhana, L. (1996). Source apportionment of atmospheric polycyclic aromatic hydrocarbons collected from an urban location in Birmingham, UK. Environ. Sci. Technol. 30: 825-832.

Heo, J.B., Hopke, P. and Yi, S.M. (2009). Source apportionment of $\mathrm{PM}_{2.5}$ in Seoul, Korea. Atmos. Chem. Phys. 9: 4957-4971.

Hong, S.B., Kang, C.H., Kim, W.H., Kim, Y.P., Yi, S.M., Ghim, Y.S., Song, C.H., Jung, C.H. and Hong, J.H. (2009). PAHs concentrations of $\mathrm{PM}_{10}$ in Seoul metropolitan area. J. Korean Soc. Atmos. Environ. 25: 347-359.

IEA (International Energy Agency) (2016). http://www. iea.org/statistics/statisticssearch/report/? country $=\mathrm{CHIN}$ A\&product $=$ balances\&year $=2000$

In, H.J., Kim, Y.P. and Lee, K.H. (2009). Enhancement of aerosol concentration in Korea due to the Northeast Asian forest fire in May 2003. Asian J. Atmos. Environ. 3: $1-8$.

Jung, D.B., Cho, Y.S., Kim, I.S., Lee, J.Y. and Kim, Y.P. (2015). Impact of energy consumption in northeast Asia to the particulate PAHs levels and composition in Seoul. Aerosol Air Qual. Res. 15: 2190-2199.

Kim, B.M., Seo, J., Kim, J.Y., Lee, J.Y. and Kim, Y. (2016a). Transported vs. Local contributions from secondary and biomass burning sources to $\mathrm{PM}_{2.5}$. Atmos. Environ. 144: 24-36.

Kim, B.M., Lee, S.B., Kim, J.Y., Kim, S., Seo, J., Bae, G.N. and Lee, J.Y. (2016b). A multivariate receptor modeling study of air-borne particulate PAHs: Regional contributions in a roadside environment. Chemosphere 144: 1270-1279.

Kim, I.S., Lee, J.Y. and Kim, Y.P. (2013). Impact of polycyclic aromatic hydrocarbon (PAH) emissions from North Korea to the air quality in the Seoul metropolitan area, South Korea. Atmos. Environ. 70: 159-165.

Kim, I.S., Wee, D., Kim, Y.P. and Lee, J.Y. (2016c), Development and application of three-dimensional potential source contribution function (3D-PSCF). Environ. Sci. Pollut. Res. 23: 16946-16954.

Kim, Y.P. (2006). Air pollution in Seoul caused by aerosols. J. Korean Soc. Atmos. Environ. 22: 535-553.

Kim, Y.P. and Lee, G. (2018). Trend of air quality in Seoul: Policy and science. Aerosol Air Qual. Res. 18: 21412156.

KMA (Korea Meterological Administration) (2016). http://www.kma.go.kr/weather/observation/currentweath er.jsp, Last Access: 23 November 2016.

Lee, E., Chan, C.K. and Paatero, P. (1999). Application of positive matrix factorization in source apportionment of particulate pollutants in Hong Kong. Atmos. Environ. 33: 3201-3212.

Lee, J.H., Gigliotti, C.L., Offenberg, J.H., Eisenreich, S.J. and Turpin, B.J. (2004). Sources of polycyclic aromatic hydrocarbons to the Hudson River Airshed. Atmos. Environ. 38: 5971-5981.

Lee, J.Y. and Kim, Y.P. (2007). Source apportionment of the particulate PAHs in Seoul, Korea: Impact of long range transport to a megacity. Atmos. Chem. Phys. 7: 3587-3596.

Lee, J.Y., Kim, Y.P. and Kang, C.H. (2011). Characteristics of the ambient particulate PAHs in Seoul, a mega city of northeast Asia in comparison with the characteristics of a background site. Atmos. Res. 99: 50-56.

Lee, S., Liu, W., Wang, Y., Russell, A.G. and Edgerton, E.S. (2008). Source apportionment of $\mathrm{PM}_{2.5}$ : Comparing $\mathrm{PMF}$ and $\mathrm{CMB}$ results for four ambient monitoring sites in the southeastern United States. Atmos. Environ. 42: 4126-4137.

Lei, Y., Zhang, Q., He, K.B. and Streets, D.G. (2011). Primary anthropogenic aerosol emission trends for China, 1990-2005. Atmos. Chem. Phys. 11: 931-954. 
Marr, L.C., Dzepina, K., Jimenez, J.L., Reisen, F., Bethel, H.L., Arey, J., Gaffney, J.S., Marley, N.A., Molina, L.T. and Molina, M.J. (2006). Sources and transformations of particle-bound polycyclic aromatic hydrocarbons in Mexico City, Atmos. Chem. Phys. 6: 1733-1745.

MOLIT (Ministry of Land, Infrastructure and Transport) (2016). http://www.index.go.kr/potal/main/EachDtlPage Detail.do?idx cd=1257, Last Access: 23 June 2016.

NBS (National Bureau of Statistics of China) (2016). China statistical year book-2014. China Statistics Press, http://www.stats.gov.cn/tjsj/ndsj/2014/indexch.htm, Last Access: 23 June 2016.

NIER (National Institute of Environmental Research). (2014). A study on introducing the global technical regulation and reducing vehicle emission effectively in real-driving condition.

Norris, G., Duvall, R., Brown, S. and Bai, S. (2014). EPA Positive Matrix Factorization (PMF) 5.0 fundamentals and user guide prepared for the US environmental protection agency office of research and development, Washington, DC EPA/600/R-14/108.

Paatero, P. (1997). Least squares formulation of robust non-negative factor analysis. Chemom. Intell. Lab. Syst. 37: $23-35$.

Paatero, P. and Tapper, U. (1994). Positive matrix factorization: A non-negative factor model with optimal utilization of error estimates of data values. Environmetrics 5: 111-126.

Paatero, P., Eberly, S., Brown, S. and Norris, G. (2014). Methods for estimating uncertainty in factor analytic solutions. Atmos. Meas. Tech. 7: 781-797.

Ravindra, K., Sokhi, R. and Van Grieken, R. (2008). Atmospheric polycyclic aromatic hydrocarbons: Source attribution, emission factors and regulation. Atmos. Environ. 42: 2895-2921.

Riddle, S.G., Robert, M.A., Jakober, C.A., Hannigan, M.P. and Kleeman, M.J. (2007). Size distribution of trace organic species emitted from heavy-duty diesel vehicles. Environ. Sci. Technol. 41: 1962-1969.

Seinfeld, J.H. and Pandis, S.N. (2016). Atmospheric chemistry and physics: From air pollution to climate change, third ed. John Wiley \& Sons, New Jersey, USA.

Shen, H., Huang, Y., Wang, R., Zhu, D., Li, W., Shen, G., Wang, B., Zhang, Y., Chen, Y., Lu, Y., Chen, H., Li, T., Sun, K., Li, B., Liu, W., Liu, J. and Tao, S. (2013). Global atmospheric emissions of polycyclic aromatic hydrocarbons from 1960 to 2008 and future predictions. Environ. Sci. Technol. 47: 6415-6424.

Shen, H. (2016). Polycyclic aromatic hydrocarbons: Their global atmospheric emissions, transport, and lung cancer risk. Springer, Berlin.

Simcik, M.F., Eisenreich, S.J. and Lioy, P.J. (1999). Source apportionment and source/sink relationships of PAHs in the coastal atmosphere of Chicago and Lake Michigan. Atmos. Environ. 33: 5071-5079.

Sofowote, U.M., Hung, H., Rastogi, A.K., Westgate, J.N., Deluca, P.F., Su, Y. and McCarry, B.E. (2011). Assessing the long-range transport of PAH to a sub-arctic site using positive matrix factorization and potential source contribution function. Atmos. Environ. 45: 967-976.

Standing Committee of the National People's Congress (1996). Law of the People's Republic of China on the coal industry, Law Press, Beijing, China, No. 75.

Stein, A.F., Draxler, R.R., Rolph, G.D., Stunder, B.J., Cohen, M.D. and Ngan, F. (2015). NOAA's HYSPLIT atmospheric transport and dispersion modeling system. Bull. Am. Meteorol. Soc. 96: 2059-2077.

Timilsina, G.R. and Dulal, H.B. (2009). A review of regulatory instruments to control environmental externalities from the transport sector. Policy research working paper. No. WPS 4867; Paper is funded by the Knowledge for Change Program (KCP). World Bank, Washington, DC, USA.

U.S. EPA (United States Environmental Protection Agency). (1998). Locating and estimating air emission from sources of polycyclic organic matter. EPA-454/R-98014. http://www.epa.gov/ttn/chief.

von Hippel, D. and Hayes, P. (2012). Foundations of energy security for the DPRK: 1990-2009 energy balances, engagement options, and future paths for energy and economic redevelopment. Nautilus Institute Special Report: Sustainability (NIfSa).

Wu, X., Wu, Y., Zhang, S., Liu, H., Fu, L. and Hao, J. (2016). Assessment of vehicle emission programs in China during 1998-2013: Achievement, challenges and implications. Environ. Pollut. 214: 556-567.

Xu, S., Liu, W. and Tao, S. (2006). Emission of polycyclic aromatic hydrocarbons in China. Environ. Sci. Technol. 40: 702-708.

Yan, Y., He, Q., Guo, L., Li, H., Zhang, H., Shao, M. and Wang, Y. (2017). Source apportionment and toxicity of atmospheric polycyclic aromatic hydrocarbons by PMF: Quantifying the influence of coal usage in Taiyuan, China. Atmos. Res. 193: 50-59.

Yang, H.H., Lai, S.O., Hsieh, L.T., Hsueh, H.J. and Chi, T. (2002). Profiles of PAH emission from steel and iron industries. Chemosphere 48: 1061-1074.

Yuan, B., Shao, M., Gouw, J., Parrish, D.D., Lu, S., Wang, M., Zeng, L., Zhang, Q., Song, Y. and Zhang, J. (2012). Volatile organic compounds (VOCs) in urban air: How chemistry affects the interpretation of positive matrix factorization (PMF) analysis. J. Geophys. Res. 117: D24302.

Zhang, Y. and Tao, S. (2009). Global atmospheric emission inventory of polycyclic aromatic hydrocarbons (PAHs) for 2004. Atmos. Environ. 43: 812-819.

Zhang, Y.X., Tao, S., Cao, J. and Coveney, R.M. (2007). Emission of polycyclic aromatic hydrocarbons in China by county. Environ. Sci. Technol. 41: 683-687.

Zhang, Y., Guo, C.S., Xu, J., Tian, Y.Z., Shi, G.L. and Feng, Y.C. (2012). Potential source contributions and risk assessment of PAHs in sediments from Taihu Lake, China: comparison of three receptor models. Water Res. 46: 3065-3073.

Zhao, Y., Zhang, J. and Nielsen, C.P. (2013). The effects of recent control policies on trends in emissions of anthropogenic atmospheric pollutants and $\mathrm{CO}_{2}$ in China. Atmos. Chem. Phys. 13: 487-508. 
Zheng, B., Tong, D., Li, M., Liu, F., Hong, C., Geng, G., Li, H., Li, X., Peng, L., Qi, J., Yan, L., Zhang, Y., Zhao, H., Zheng, Y., He, K. and Zhang, Q. (2018). Trends in China's anthropogenic emissions since 2010 as the consequence of clean air actions. Atmos. Chem. Phys. 18: 14095-14111.

Zheng, M., Salmon, L.G., Schauer, J.J., Zeng, L., Kiang, C., Zhang, Y. and Cass, G.R. (2005). Seasonal trends in
$\mathrm{PM}_{2.5}$ source contributions in Beijing, China. Atmos. Environ. 39: 3967-3976.

Received for review, June 22, 2018 Revised, September 22, 2018 Accepted, September 232018 